\title{
Primary Care Management of Chronic Kidney Disease
}

\author{
Adrienne S. Allen, $M D^{7,3,5}$, John P. Forman, $M D, M S c^{2,3,5}$, E. John Orav, $P h D^{7,3}$, \\ David W. Bates, MD, MSc ${ }^{1,3,4}$, Bradley M. Denker, MD ${ }^{2,3,5}$, and Thomas D. Sequist, MD, MPH ${ }^{1,3,5}$
}

'Division of General Medicine, Brigham and Women's Hospital, Boston, MA, USA; ²Renal Division, Brigham and Women's Hospital, Boston, MA, USA; ${ }^{3}$ Harvard Medical School, Boston, MA, USA; ${ }^{4}$ Department of Health Policy and Management, Harvard School of Public Health, Boston, MA, USA; ${ }^{5}$ Harvard Vanguard Medical Associates, Boston, MA, USA.

BACKGROUND: Chronic kidney disease (CKD) causes substantial morbidity and mortality; however, there are limited data to comprehensively assess quality of care in this area.

OBJECTIVE: To assess quality of care for CKD according to patient risk and identify correlates of improved care delivery.

DESIGN: Retrospective cohort.

SETTING: Fifteen health centers within a multi-site group practice in eastern Massachusetts.

PARTICIPANTS: 166 primary care physicians caring for 11,774 patients with stages 3 or 4 CKD defined as two estimated glomerular filtration rates (eGFR) between 15 and 60.

MAIN MEASURES: Two measures of kidney disease monitoring, five measures of cardiovascular disease management, four measures of metabolic bone disease and anemia management, and one measure of drug safety were extracted from the electronic health record. Primary care recognition of $\mathrm{CKD}$ was assessed as a problem list diagnosis, and nephrology co-management was assessed as at least one visit with a nephrologist in the prior 12 months.

KEY RESULTS: Overall, 46\% of patients were high risk for death based on the presence of diabetes, proteinuria, or an eGFR <45. Seventy percent of patients lacked annual urine protein testing, 46\% had a blood pressure $\geq 130 / 80 \mathrm{mmHg}$ and $25 \%$ were not receiving appropriate angiotensin blockade. Appropriate screening for anemia was common (76\%), while screening rates for metabolic bone disease were low. Use of potentially harmful drugs was common (26\%). Primary care physician recognition and nephrology co-management were both associated with improved quality of care, though rates of both were low (24\% and $10 \%$, respectively).

CONCLUSIONS: Significant deficiencies in the quality of CKD care exist. Opportunities for improvement include increasing physician recognition of CKD and improving collaborative care with nephrology.

KEY WORDS: chronic kidney disease; primary care; quality of care; performance measurement.

Received June 21, 2010

Revised September 10, 2010

Accepted September 13, 2010

Published online October 5, 2010
J Gen Intern Med 26(4):386-92

DOI: $10.1007 / \mathrm{s} 11606-010-1523-6$

(c) Society of General Internal Medicine 2010

\section{INTRODUCTION}

Chronic kidney disease (CKD) affects approximately 13\% of the adult population, resulting in significant morbidity, mortality and health care costs. ${ }^{1}$ Patients with more progressive stage 3 or stage $4 \mathrm{CKD}$ [estimated glomerular filtration rate (eGFR) between 15 and $60 \mathrm{ml} / \mathrm{min} / 1.73 \mathrm{~m}^{2}$ ] experience a high rate of cardiovascular events and death compared to earlier stages of CKD (eGFR >60).$^{2-4}$ Practice guidelines promote monitoring for progressive kidney disease in these patients, as well as aggressive management of cardiovascular risk and the complications of metabolic bone disease and anemia. ${ }^{2,5}$ Such early interventions can prevent excess cardiovascular mortality and limit progression to end-stage renal disease, ${ }^{2,6}$ highlighting the importance of focusing on this higher risk population.

Primary care physicians (PCPs) represent the front line in the early identification and management of CKD. However, most PCPs do not consistently identify the presence of $\mathrm{CKD} .{ }^{7-}$

${ }^{11}$ In addition, while increased involvement of nephrologists in the management of these patients has been linked to improved dialysis-free survival, ${ }^{12}$ the majority of patients with stages 3 and $4 \mathrm{CKD}$ are not co-managed by nephrologists. ${ }^{12,13}$

There are limited population-based data available to comprehensively assess quality of CKD care ${ }^{14}$ and the effects of physician recognition and nephrology co-management on care delivery patterns. ${ }^{15}$ The goals of our study were to assess the quality of care for chronic kidney disease in routine clinical practice and to identify patient and clinical features associated with delivery of high quality care.

\section{METHODS}

\section{Study Setting}

The study was conducted within a multi-specialty group practice consisting of 15 ambulatory health centers in Massachusetts, with 166 PCPs caring for approximately 300,000 adult patients. The practices use a common electronic health record (Epic Systems) that captures clinical notes and electronic diagnosis 
codes, specialty referrals, medication prescriptions and laboratory test results. Electronic problem lists are primarily maintained by PCPs. This system has delivered automated reporting of eGFR, computed using the Modification of Diet in Renal Disease Study equation, ${ }^{16}$ along with serum creatinine, since 2007 . The electronic health record does not provide decision support for patients with CKD. Nephrology services are provided by eight nephrologists within the group practice.

\section{Patient Eligibility}

We used electronic medical record data to identify patients with stages 3 or $4 \mathrm{CKD}$, defined as two consecutive eGFRs between 15 and 60 separated by at least 90 days, ${ }^{2}$ occurring during a 4-year interval from 2004 to 2008 . We did not include patients with stages 1 or 2 CKD based on their lower overall risk for complications and the difficulty in accurately identifying these patients using the eGFR. We excluded stage 5 CKD patients as they are managed primarily by nephrologists, with complex care processes typically outside of the domain of primary care. We excluded children $<18$ years old, patients lacking a primary care visit within the most recent 18 months of the 4-year enrollment period, and patients receiving renal replacement therapy based on diagnosis codes and dialysis encounters.

\section{Quality Measures}

We evaluated the quality of care in four primary domains, ${ }^{2}$ including (1) monitoring stage of CKD, (2) cardiovascular risk management, (3) metabolic bone disease and anemia monitoring and (4) drug safety. All measures were assessed in the year following July 1,2008 to allow a minimum of 1 year following the initial diagnosis of $\mathrm{CKD}$ prior to assessing clinical performance.

Monitoring of disease stage was assessed as annual testing for eGFR and urine protein. Cardiovascular risk management was evaluated as annual monitoring of LDL cholesterol, appropriate use of ACE-inhibitors/angiotensin receptor blockers (ARB), appropriate use of lipid-lowering therapy (statins), and achieving an LDL cholesterol $<100 \mathrm{mg} / \mathrm{dl}$ and blood pressure $<130 / 80 \mathrm{mmHg}$. Appropriate use of ACE inhibitor/ ARB was defined as a prescription within the last 12 months for patients with hypertension, diabetes, urine protein/creatinine ratio $>0.15$ or a spot urine albumin/creatinine ratio $>30 \mathrm{mcg} / \mathrm{mg}$, and no documented drug allergy. Appropriate use of statins was defined as a prescription within the last 12 months for patients with an LDL cholesterol $>100 \mathrm{mg} / \mathrm{dl}$ and no documented drug allergy.

Prevention of metabolic bone disease was assessed as annual testing for calcium, phosphorous, parathyroid hormone (PTH) and 25-hydroxyvitamin D. Anemia monitoring was assessed as annual monitoring of hemoglobin. Drug safety was examined via electronic prescription rates of potentially inappropriate medications within the prior 12 months, including non-steroidal anti-inflammatory drugs (NSAIDs), glyburide, metformin, nitrofurantoin, terbinafine (eGFR <50), alendronate $(\mathrm{eGFR}<35)$, ibandronate $(\mathrm{eGFR}<30)$ and risedronate
(eGFR <35). These drugs were identified based on expert consensus and review of the medical literature.

\section{Correlates of quality of care}

We collected patient level sociodemographic features, including age, sex, race and insurance status from the electronic health record. We assessed comorbid conditions including diabetes, hypertension and coronary artery disease. Diabetes was defined as the presence of either a diagnosis of diabetes on the electronic problem list, or at least three encounter diagnoses in the prior 24 months, or a hemoglobin Alc result $>7 \%$. Hypertension was defined as a diagnosis on the electronic problem list or at least three encounter diagnoses in the prior 24 months. Coronary artery disease was defined based on diagnoses codes according to Healthcare Effectiveness Data and Information Set (HEDIS) criteria. ${ }^{17}$

We analyzed CKD care according to risk for overall mortality or progression to end-stage renal disease, with high risk patients defined as those with (1) concurrent diabetes ${ }^{18,19}$; (2) urine protein/creatinine ratio greater than 0.15 or a spot urine albumin/creatinine ratio $>30 \mathrm{mcg} / \mathrm{mg}^{20}$; or (3) eGFR $<45 .{ }^{12}$

We defined PCP recognition as documentation of a CKD diagnosis on the electronic problem list. ${ }^{21-23}$ We defined the degree of nephrology involvement as (1) active co-management (nephrology visit within the prior 12 months), (2) past nephrology care (nephrology visit more than 12 months prior), or (3) no prior nephrology visits.

\section{Data analysis}

We analyzed correlates of performance on each quality measure by fitting hierarchical logistic regression models implemented via SAS PROC GLIMMIX to adjust for clustering within health centers and primary care physicians. These models included performance on each clinical measure as the binary dependent variable. To compare the care of high risk patients versus low risk patients, we fit a model for each clinical measure with patient risk status as the primary independent variable. Additional independent variables included patient age, sex, race and insurance status; presence of hypertension or coronary artery disease; presence of CKD on the problem list; and degree of nephrology involvement.

We fit a second set of models to evaluate patient sociodemographic and clinical correlates of CKD care, with performance of each clinical measure as the binary dependent variable. Independent variables included patient age, sex, race and insurance status; presence of diabetes; presence of hypertension; presence of coronary artery disease; presence of CKD on the problem list; and degree of nephrology involvement. We used SAS PROC GLIMMIX to output predicted rates of clinical performance for each quality measure after adjusting for all patient and clinical characteristics.

We analyzed factors associated with degree of nephrology involvement by fitting a hierarchical logistic regression model including patient age, sex, race and insurance status; patient risk status; presence of hypertension or coronary artery disease; and the presence of $\mathrm{CKD}$ on the problem list. We analyzed factors related to the presence of CKD on the problem 
list by fitting a final hierarchical logistic regression model adjusting for patient age, sex, race and insurance status; patient risk status; and presence of hypertension or coronary artery disease. We did not include nephrology co-management in this model as PCPs would most likely be aware of the diagnosis of CKD before referring to nephrology.

This study protocol was approved by the Institutional Review Board at Brigham and Women's Hospital. All analyses were conducted using SAS version 9.2.

\section{RESULTS}

We identified 11,774 patients with stage $3(97 \%)$ or stage $4(3 \%)$ CKD (Table 1). Coexisting diabetes (29\%) and hypertension $(66 \%)$ were common. Nearly one-half $(46 \%)$ of patients were defined as high risk for mortality based on the presence of diabetes, proteinuria or eGFR $<45$. Only $24 \%$ of patients with CKD had their condition documented on the problem list, and only $10 \%$ were actively co-managed with nephrology within the prior 12 months.

\section{Chronic Kidney Disease Care}

The majority of patients received annual monitoring of eGFR, though less than one-third (30\%) received annual urine protein testing (Table 2). Three-quarters of patients were receiving appropriate ACE-I/ARB therapy and had annual LDL cholesterol testing, although the proportions of patients with good blood pressure control and LDL cholesterol control were lower. Among patients with diabetes, 53\% achieved ideal

Table 1. Sociodemographic and Clinical Characteristics of Study Population

\begin{tabular}{|c|c|}
\hline & Overall $(n=11,774)$ \\
\hline \multicolumn{2}{|l|}{ Sociodemographic characteristics } \\
\hline Mean age, years (SD) & $73.3(12)$ \\
\hline Male, n (\%) & $4,704(40)$ \\
\hline \multicolumn{2}{|l|}{ Race, n (\%) } \\
\hline White & $9,706(84)$ \\
\hline Black & $848(7)$ \\
\hline Asian & $272(2)$ \\
\hline Hispanic & $193(2)$ \\
\hline Other & $476(4)$ \\
\hline \multicolumn{2}{|l|}{ Insurance, n (\%) } \\
\hline Medicare & $7,779(69)$ \\
\hline Commercial & $3,215(28)$ \\
\hline Medicaid & $236(2)$ \\
\hline Uninsured & $106(1)$ \\
\hline \multicolumn{2}{|l|}{ Comorbid conditions, $\mathrm{n}(\%)$} \\
\hline Hypertension & $7,737(66)$ \\
\hline Coronary artery disease & $5,665(48)$ \\
\hline Diabetes & $3,410(29)$ \\
\hline \multicolumn{2}{|l|}{ Chronic kidney disease stage, n (\%) } \\
\hline Stage $3(30 \leq \text { eGFR }<60)^{*}$ & $11,379(97)$ \\
\hline Stage $4(15 \leq \text { eGFR }<30)^{*}$ & $395(3)$ \\
\hline \multicolumn{2}{|l|}{ Risk status, n (\%) } \\
\hline $\mathrm{High}^{\dagger}$ & $5,469(46)$ \\
\hline Low & $6,305(54)$ \\
\hline \multicolumn{2}{|l|}{ Clinical practice patterns, n (\%) } \\
\hline Chronic kidney disease on problem list & $2,878(24)$ \\
\hline Nephrology visit in last 12 months & $1,193(10)$ \\
\hline Nephrology visit $>12$ months prior & $1,863(16)$ \\
\hline
\end{tabular}

*Based on estimated glomerular filtration rate upon study entry $\dagger$ Based on presence of diabetes, proteinuria or eGFR $<45$
Table 2. Quality of Chronic Kidney Disease Care

\begin{tabular}{|c|c|c|c|c|}
\hline & $\begin{array}{l}\text { Overall N } \\
(\%)\end{array}$ & $\begin{array}{l}\text { High risk } \\
\%^{\dagger}\end{array}$ & $\begin{array}{l}\text { Low risk } \\
\%^{\dagger}\end{array}$ & $\begin{array}{l}P \\
\text { value }\end{array}$ \\
\hline \multicolumn{5}{|l|}{ Kidney disease monitoring } \\
\hline Annual eGFR* & $\begin{array}{l}10,092 \\
(86)\end{array}$ & 91.0 & 86.7 & $<0.01$ \\
\hline Annual urine protein & $3,477(30)$ & 53.2 & 5.7 & $<0.01$ \\
\hline \multicolumn{5}{|l|}{ Cardiovascular disease } \\
\hline $\begin{array}{l}\text { Appropriate ACE-I/ } \\
\text { ARB use }\end{array}$ & $6,131(75)$ & 75.8 & 61.1 & $<0.01$ \\
\hline $\begin{array}{l}\text { Blood pressure } \\
<130 / 80 \mathrm{mmHg}\end{array}$ & $6,338(54)$ & 55.7 & 52.2 & 0.01 \\
\hline Annual LDL cholesterol & $8,750(74)$ & 77.8 & 71.5 & $<0.01$ \\
\hline Statin use ${ }^{\S}$ & $1,961(42)$ & 49.7 & 38.0 & $<0.01$ \\
\hline $\begin{array}{l}\text { LDL cholesterol } \\
<100 \mathrm{mg} / \mathrm{dl}\end{array}$ & $5,225(44)$ & 54.9 & 34.7 & $<0.01$ \\
\hline \multicolumn{5}{|l|}{ Metabolic bone disease } \\
\hline Annual calcium & $5,287(45)$ & 48.8 & 46.5 & 0.01 \\
\hline Annual vitamin D & $2,877(24)$ & 17.8 & 21.2 & $<0.01$ \\
\hline $\begin{array}{l}\text { Annual parathyroid } \\
\text { hormone }\end{array}$ & $1,554(13)$ & 6.4 & 5.2 & 0.03 \\
\hline \multicolumn{5}{|l|}{ Anemia } \\
\hline Annual hemoglobin & $8,885(76)$ & 76.0 & 77.0 & 0.31 \\
\hline \multicolumn{5}{|l|}{ Drug safety } \\
\hline Metformin & $1,305(11)$ & 24.7 & $<1$ & $<0.01$ \\
\hline NSAID $\|$ & $1,144(10)$ & 8.0 & 10.2 & 0.01 \\
\hline Glyburide & $841(7)$ & 15.4 & $<1$ & 0.01 \\
\hline Nitrofurantoin & $378(3)$ & 2.5 & 2.1 & 0.14 \\
\hline Alendronate\# & $88(<1)$ & 2 & - & - \\
\hline Terbinafine $^{\mathrm{qI}}$ & $7(<1)$ & $<1$ & $<1$ & - \\
\hline Ibandronate** & $3(<1)$ & $<1$ & - & - \\
\hline Risedronate** & $2(<1)$ & $<1$ & - & - \\
\hline $\begin{array}{l}\text { One or more } \\
\text { inappropriate drug }\end{array}$ & $3,045(26)$ & 41.9 & 13.0 & $<0.01$ \\
\hline
\end{tabular}

*Denotes estimated glomerular filtration rate

$\dagger$ Percentages adjusted for patient age, race, gender, insurance status, hypertension, coronary artery disease, nephrology co-management and presence of CKD on the problem list

¥mong 8,045 patients with coexisting diabetes, hypertension or microalbuminuria. ACE-I denotes angiotensin-converting enzyme inhibitor, ARB denotes angiotensin receptor blocker

§Use of HMG Co-A reductase inhibitors among 4,645 patients with $L D L$ cholesterol $>100 \mathrm{mg} / \mathrm{dl}$

||Denotes non-steroidal inflammatory drug

IITerbinafine use among patients with eGFR $<50$

\#Alendronate use among patients with eGFR $<35$

**Ibandronate and risedronate use for patients with eGFR $<30$

hemoglobin Alc control. Performance measures for metabolic bone disease management were met in fewer than $50 \%$ of patients. Over one-quarter $(26 \%)$ of patients had been prescribed a potentially harmful medication in the last 12 months, with metformin most commonly prescribed.

Performance rates were significantly higher among high risk compared to low risk patients for all measures except annual hemoglobin testing (76.0\% versus $77.0 \%, \mathrm{p}=0.38$ ) and annual vitamin D measurement, which was significantly lower for high risk patients $(17.8 \%$ versus $21.2 \%, \mathrm{p}<0.01)$. High risk patients were more likely to be prescribed inappropriate medications (41.7\% versus $13.1 \%, \mathrm{p}<0.01)$, which was driven by the use of metformin and glyburide in higr risk diabetic patients. There was no difference in rates of inappropriate medications between high risk patients without diabetes and low risk patients $(13.8 \%$ vs. $14.0 \%, \mathrm{p}=0.88)$. 
Younger, black and female patients were all less likely to achieve targeted levels of LDL cholesterol and blood pressure control (Table 3). Uninsured patients demonstrated lower rates than insured patients for kidney disease monitoring and three of the five measures of cardiovascular risk management. Patients with co-existing diabetes, hypertension or coronary artery disease were significantly more likely than those without to receive adequate kidney disease monitoring and cardiovascular management.

\section{Primary Care Physician Recognition and Nephrology Involvement}

Patient features significantly associated with increased PCP recognition of CKD included black race [odds ratio (OR) 2.71, 95\% confidence interval (CI) 2.2-3.3], male gender (OR 2.42, 95\% CI 2.2-2.7), presence of hypertension (OR 1.53, 95\% CI 1.3-1.7) and high risk status (OR 8.11, 95\% CI 7.2-9.1). Predictors of active nephrology co-management within the prior 12 months included age less than 65 years (OR 1.97, 95\% CI 1.5-2.5), male gender (OR 1.45, 95\% CI 1.2-1.7) presence of hypertension (OR 2.05, 95\% CI 1.7-2.5), high risk status (OR 4.58, 95\% CI 3.7-5.7) and primary care recognition of CKD (OR 12.18, 95\% CI 10.2-14.6).

Primary care physician recognition and nephrology involvement were both associated with increased kidney disease monitoring, monitoring for metabolic bone disease and anemia, and improved drug safety (Table 4). Active co-management by nephrology within the prior 12 months was more consistently associated with improved CKD care compared to past nephrology involvement $(<12$ months). Primary care physician recognition and active nephrology co-management were associated with increased ACE-I/ARB use. Neither increased physician recognition nor active nephrology comanagement was associated with improved blood pressure or cholesterol control.

\section{DISCUSSION}

Chronic kidney disease represents a significant health care issue, affecting $13 \%$ of the population, resulting in substantial mortality and health care costs. ${ }^{1,24,25}$ We identified a large, primary care-based population with CKD and found significant deficiencies in clinical care. Patients with high risk disease features for cardiovascular death, such as diabetes, proteinuria or an eGFR $<45$, were managed more aggressively, as were those patients for whom the PCP recognized the diagnosis or were being actively co-managed with nephrology. Unfortunately, most PCPs did not appear to recognize the underlying presence of $\mathrm{CKD}$, and relatively few patients were managed with nephrology involvement. Our study is consis-

Table 3. Patient Sociodemographic and Clinical Predictors of Chronic Kidney Disease Care*

\begin{tabular}{|c|c|c|c|c|c|c|c|}
\hline \multirow[b]{2}{*}{ Predictor } & \multicolumn{2}{|c|}{$\begin{array}{l}\text { Kidney disease } \\
\text { monitoring, \% }\end{array}$} & \multicolumn{5}{|c|}{ Cardiovascular disease management, \% } \\
\hline & $\begin{array}{l}\text { Annual } \\
\text { eGFR }\end{array}$ & $\begin{array}{l}\text { Annual urine } \\
\text { protein }\end{array}$ & $\begin{array}{l}\text { ACE-I/ ARB } \\
\text { use }^{\ddagger}\end{array}$ & $\begin{array}{l}\text { Blood pressure }<130 / 80 \\
\mathrm{mmHg}\end{array}$ & $\begin{array}{l}\text { Annual LDL } \\
\text { cholesterol }\end{array}$ & $\begin{array}{l}\text { Statin } \\
\text { use }^{\S}\end{array}$ & $\begin{array}{l}\mathrm{LDL}<100 \\
\mathrm{mg} / \mathrm{dl}\end{array}$ \\
\hline \multicolumn{8}{|l|}{ Patient age } \\
\hline$\leq 65$ years & 89.2 & 20.7 & 68.9 & $56.9^{*}$ & 73.7 & 39.2 & 38.7* \\
\hline$>65$ years & 88.5 & 20.0 & 71.5 & 52.9 & 75.8 & 43.1 & 46.1 \\
\hline \multicolumn{8}{|l|}{ Patient race } \\
\hline Black & 87.9 & 22.7 & 73.3 & 46.1* & 72.4* & 41.3 & 32.3* \\
\hline Other race & 89.4 & $25.7 *$ & 73.9 & 53.8 & 75.8 & 42.4 & 41.0* \\
\hline White (reference) & 89.1 & 19.5 & 70.4 & 54.6 & 75.5 & 41.8 & 45.6 \\
\hline \multicolumn{8}{|l|}{ Patient gender } \\
\hline Male & 89.1 & 24.4* & 72.2 & 56.5* & 76.6* & 39.4 & 51.4* \\
\hline Female & 89.0 & 17.7 & 70.1 & 52.2 & 74.5 & 42.9 & 39.7 \\
\hline \multicolumn{8}{|l|}{ Insurance } \\
\hline Medicare & 89.7 & 20.1 & 69.8* & 54.6 & 74.6 & 42.0 & 44.8 \\
\hline Medicaid & 90.1 & 23.3 & 76.5 & 48.6 & 82.9* & 42.4 & 48.5 \\
\hline Uninsured & 63.6* & $6.2^{*}$ & 57.5* & 57.9 & 45.1* & 35.7 & $25.7^{*}$ \\
\hline Commercial (reference) & 87.7 & 20.9 & 74.2 & 52.4 & 77.2 & 41.7 & 43.2 \\
\hline \multicolumn{8}{|l|}{ Comorbid conditions } \\
\hline \multicolumn{8}{|l|}{ Diabetes } \\
\hline Present & 92.8* & 76.1* & $81.7 *$ & 57.0* & 85.6* & 65.6* & 66.0* \\
\hline Absent & 88.4 & 8.2 & 62.1 & 52.6 & 69.9 & 37.9 & 35.5 \\
\hline \multicolumn{8}{|l|}{ Hypertension } \\
\hline Present & 91.9* & 23.8* & 73.5* & $50.1^{*}$ & 78.4* & 47.5* & $48.2^{*}$ \\
\hline Absent & 81.1 & 14.3 & 41.7 & 61.2 & 68.5 & 34.4 & 36.8 \\
\hline \multicolumn{8}{|l|}{$\mathrm{CAD}^{+}$} \\
\hline Present & 89.9* & 19.8 & 71.7 & 57.0* & 76.4* & 51.8* & 51.9* \\
\hline Absent & 88.2 & 20.5 & 70.1 & 50.9 & 74.3 & 37.1 & 37.1 \\
\hline
\end{tabular}

*Percentages in bold indicate statistically significant differences with $\mathrm{p}<0.05$ after adjusting for patient age, race, gender, insurance status, diabetes, hypertension, coronary artery disease, nephrology co-management and presence of CKD on the problem list $\dagger$ Denotes coronary artery disease

$\ddagger$ Among 8,045 patients with coexisting diabetes, hypertension or microalbuminuria. ACE-I denotes angiotensin-converting enzyme inhibitor, ARB denotes angiotensin receptor blocker

§Use of HMG Co-A reductase inhibitors among 4,645 patients with LDL cholesterol $>100 \mathrm{mg} / \mathrm{dl}$ 
Table 4. Importance of Awareness of Chronic Kidney Disease and Nephrology Involvement

\begin{tabular}{|c|c|c|c|c|c|}
\hline & \multicolumn{2}{|c|}{$\begin{array}{l}\text { Primary care physician } \\
\text { recognition }\end{array}$} & \multicolumn{3}{|c|}{ Nephrology involvement } \\
\hline & Present \%" & Absent \%" & Current (<12 months) & Past (>12 months) \%" & Never \%* \\
\hline \multicolumn{6}{|l|}{ Kidney disease monitoring } \\
\hline Annual $\mathrm{eGFR}^{\dagger}$ & 93.1 & 88.8 & 99.0 & 85.0 & 87.4 \\
\hline Annual urine protein & 27.8 & 18.6 & 88.7 & 25.7 & 14.6 \\
\hline \multicolumn{6}{|l|}{ Cardiovascular disease } \\
\hline Appropriate ACE-I/ARB use ${ }^{\neq}$ & 74.1 & 69.7 & 81.0 & 70.8 & 69.1 \\
\hline Blood pressure <130/80 mmHg & 53.3 & 54.1 & 55.8 & 53.8 & 53.7 \\
\hline Annual LDL cholesterol & 76.0 & 75.2 & 77.7 & 73.1 & 75.2 \\
\hline Statin use $\mathrm{e}^{\S}$ & 41.2 & 42.0 & 40.1 & 37.9 & 42.2 \\
\hline LDL cholesterol $<100 \mathrm{mg} / \mathrm{dl}$ & 45.5 & 43.9 & 47.1 & 43.1 & 44.0 \\
\hline \multicolumn{6}{|l|}{ Metabolic bone disease } \\
\hline Annual calcium & 56.4 & 45.3 & 93.4 & 50.1 & 40.0 \\
\hline Annual vitamin D & 26.1 & 18.3 & 88.8 & 24.1 & 14.1 \\
\hline Annual parathyroid hormone & 13.0 & 4.7 & 78.1 & 11.5 & 3.8 \\
\hline \multicolumn{6}{|l|}{ Anemia } \\
\hline Annual hemoglobin & 80.3 & 76.1 & 96.5 & 75.7 & 72.7 \\
\hline \multicolumn{6}{|l|}{ Drug safety } \\
\hline One or more inappropriate drug & 19.7 & 23.9 & 17.5 & 18.1 & 23.8 \\
\hline
\end{tabular}

*Percentages adjusted for patient age, race, gender, insurance status, diabetes, hypertension, coronary artery disease, nephrology co-management and presence of CKD on the problem list. Percentages in bold indicate statistically significant differences $(p<0.05)$

$\dagger$ Denotes estimated glomerular filtration rate

\$Among 8,045 patients with coexisting diabetes, hypertension or microalbuminuria. ACE-I denotes angiotensin converting enzyme inhibitor, ARB denotes angiotensin receptor blocker

$\S$ Use of HMG Co-A reductase inhibitors among 4,645 patients with $\mathrm{LDL}$ cholesterol $>100 \mathrm{mg} / \mathrm{dl}$

tent with the prior CKD literature documenting significant deficits in the management of cardiovascular risk factors, ${ }^{23,26-}$ ${ }^{28}$ monitoring for proteinuria and ACE-I/ARB therapy ${ }^{13,23}$ and screening for metabolic bone disease. ${ }^{29}$ Our analyses expand on this prior work by using detailed electronic health record data to risk stratify a large patient population and to comprehensively assess care across a broad spectrum of domains, including drug safety.

As health care delivery systems seek to implement CKD management programs, determining cost-effective resource allocation will be essential. ${ }^{23,30}$ To meet this goal, we developed an algorithm that identified patients at high risk for death. Management programs may elect to target these high risk patients or specific areas where gaps are the greatest. The development of new CKD chronic care management programs should also focus on meeting the needs of underserved populations. We found that women and black patients were less likely to achieve important clinical targets including blood pressure and cholesterol control. These disparities are consistent with prior literature regarding chronic disease management and may require specific efforts to eliminate these gaps. ${ }^{31}$

Because recognition of CKD was so low, much of the CKD management seen in this study was likely performed as part of care for known diabetes or cardiovascular disease. Many of the care recommendations specific to $\mathrm{CKD}$ such as management of metabolic bone disease were not performed. Patients did receive better care when their $\mathrm{CKD}$ was recognized. This suggests that PCPs should be assisted with identification of patients with CKD. Automated reporting of eGFR represents one potential method of accomplishing this, ${ }^{22,32,33}$ but our data and prior literature suggest it is not sufficient. ${ }^{22}$ More advanced clinical decision support within the context of electronic health records could be used both to highlight the presence of CKD and to suggest specific targeted treatment recommendations.

Our data highlight that clinicians are less likely to recognize the presence of CKD among white patients, women and those without hypertension, diabetes, proteinuria or low eGFRs $(<45)$. PCPs may perceive these patients as being lower risk for developing $\mathrm{CKD}$. Alternatively, physicians may rely primarily on serum creatinine thresholds rather than eGFR. In this case, women and white patients will be less likely to cross such a creatinine threshold for a given eGFR compared to male and black patients, making recognition of underlying CKD less likely.

We confirmed the low prevalence of involvement of nephrologists in the management of $\mathrm{CKD},{ }^{12,13}$ despite the known survival benefit of such involvement for patients with stages 3 and $4 \mathrm{CKD}$. Nephrology involvement of any type was associated with improved care across many measures, with the most improvement seen among patients with a recent nephrology visit. While higher rates of nephrology co-management were appropriately seen among the higher risk patients, we found that older patients were referred less often, perhaps due to hesitancy on the part of PCPs that such care targets predialysis care only. ${ }^{34,35}$ Older patients with low eGFR or albuminuira still have increased risk of death, ${ }^{4,36}$ and nephrology care has been shown to improve dialysis-free mortality. ${ }^{12}$ Programs to increase appropriate involvement of nephrologists should focus on increased communication between PCPs and nephrologists about goals of co-managed CKD care, especially for high risk patients. ${ }^{37}$ However, better management by primary care must represent an important 
component of any strategy as the supply of nephrologists is limited.

We found that $27 \%$ of patients were prescribed potentially unsafe or nephrotoxic medications. Few studies have documented the use of unsafe medications in the primary care setting based on renal function. While we did not assess the frequency of harm caused by these medications, our data highlight a major patient safety concern, particularly given that we likely underestimated use by not capturing over-thecounter NSAID use. Efforts to improve drug safety might take the form of real-time, patient-specific clinical decision support, ${ }^{38}$ supplemented by regular population-level monitoring with notification of both patients and providers of potentially inappropriate medications. ${ }^{39}$

An important finding is that rates of ideal blood pressure control were low, and we did not identify any significant predictors of improved control. Nephrology co-management was associated with a clinically important increase in ACE-I/ ARB therapy, potentially due to hesitancy on the part of primary care physicians to use these medications in the setting of a rising creatinine or mild hyperkalemia. Despite this, nephrology involvement was not associated with improved blood pressure control. This demonstrates the need for a specific focus on managing hypertension in CKD and the need to overcome potential barriers such as those related to medication therapy intensification. ${ }^{40}$

While our study is strengthened by the availability of comprehensive clinical data on a large patient population, it has important limitations. We focused primarily on clinical performance measures and do not have data on long-term patient outcomes. However, the clinical performance measures we assessed have been associated with long-term outcomes in randomized trials. ${ }^{2}$ We did not include intermediate outcome targets related to anemia monitoring and metabolic bone disease. There is currently debate regarding the optimal targets for these aspects of $\mathrm{CKD},{ }^{41,42}$ and so we focused on process measures of annual monitoring, for which there is general agreement. ${ }^{2}$ We used $130 / 80 \mathrm{mmHg}$ as a target for blood pressure control based on published guidelines, ${ }^{43,44}$ though there is debate as to whether a goal of $140 / 90 \mathrm{mmHg}$ is more appropriate. ${ }^{45}$ The benefits of more aggressive blood pressure control may be more apparent in patients with significant proteinuria. ${ }^{46}$ We did not assess harm from the use of apparently unsafe medications and were unable to exclude short courses of NSAID therapy, which may be less nephrotoxic than longer therapeutic courses. Finally, our study took place in a multi-specialty group practice with integrated involvement of primary and specialty care, and the results may not apply in other practice settings. However, overall levels of performance may be even lower in less structured settings.

In summary, we identified significant challenges as well as opportunities in the management of CKD. Effective use of electronic health record data can facilitate risk stratification of patient populations and identification of gaps in quality of care. Increasing physician recognition of CKD and appropriate involvement of nephrology represent important goals to improve delivery CKD care. Additional efforts are clearly needed, including a focus on drug safety and adequately managing cardiovascular risk factors.
Acknowledgements: This study was funded by the Agency for Healthcare Research and Quality (R18 HSO18226) and by an Institutional National Research Service Award (T32HP10251-02). We would like to thank Amy Marston and Shimon Shaykevich for their efforts related to data extraction and programming.

Disclosures: Thomas Sequist serves as a consultant on the Aetna Racial and Ethnic Equality External Advisory Committee.

Conflict of Interest: David W. Bates, MD, MSc. is a coinventor on Patent No. 6029138 held by Brigham and Women's Hospital on the use of decision support software for medical management, licensed to the Medicalis Corporation. He holds a minority equity position in the privately held company Medicalis which develops web-based decision support for radiology test ordering, and has served as a consultant to Medicalis. He is on the clinical advisory board for Zynx, Inc., which develops evidence-based algorithms, and Patient Safety Systems, which provides a set of approaches to help hospitals improve safety. He consults for Hearst, which develops knowledge resources. He serves on the clinical advisory board for SEA Medical Systems, which makes intravenous pump technology. He serves on the board of Care Management International, which is involved in chronic disease management.

Corresponding Author: Adrienne S. Allen, MD, Division of General Medicine, Brigham and Women's Hospital, Boston, MA, USA (email: aallen0@partners.org).

\section{REFERENCES}

1. Coresh J, Selvin E, Stevens LA, et al. Prevalence of chronic kidney disease in the United States. Jama. 2007;298(17):2038-47.

2. K/DOgI. Clinical practice guidelines for chronic kidney disease: evaluation, classification, and stratification. Am J Kidney Dis. 2002;39(2 Suppl 1):S1-266.

3. K/DOgI. Clinical practice guidelines for management of dyslipidemias in patients with kidney disease. Am J Kidney Dis. 2003;41(4 Suppl 3): S1-91.

4. Matsushita $\mathbf{K}$, van der Velde $\mathbf{M}$, Astor BC, et al. Association of estimated glomerular filtration rate and albuminuria with all-cause and cardiovascular mortality in general population cohorts: a collaborative meta-analysis. Lancet. 2010;375(9731):2073-81.

5. Levey AS, Coresh J, Balk E, et al. National kidney foundation practice guidelines for chronic kidney disease: evaluation, classification, and stratification. Ann Intern Med. 2003;139(2):137-47.

6. Zandi-Nejad $\mathbf{K}$, Brenner BM. Strategies to retard the progression of chronic kidney disease. Med Clin North Am. 2005;89(3):489-509.

7. Minutolo R, De Nicola L, Mazzaglia G, et al. Detection and awareness of moderate to advanced CKD by primary care practitioners: a crosssectional study from Italy. Am J Kidney Dis. 2008;52(3):444-53.

8. Boulware LE, Troll MU, Jaar BG, Myers DI, Powe NR. Identification and referral of patients with progressive CKD: a national study. Am J Kidney Dis. 2006;48(2):192-204.

9. Stevens LA, Fares G, Fleming $\mathbf{J}$, et al. Low rates of testing and diagnostic codes usage in a commercial clinical laboratory: evidence for lack of physician awareness of chronic kidney disease. J Am Soc Nephrol. 2005; 16(8):2439-48.

10. Fox CH, Brooks A, Zayas LE, McClellan W, Murray B. Primary care physicians' knowledge and practice patterns in the treatment of chronic kidney disease: an Upstate New York Practice-based Research Network (UNYNET) study. J Am Board Fam Med. 2006;19 (1):54-61.

11. Lea JP, McClellan WM, Melcher C, Gladstone E, Hostetter T. CKD risk factors reported by primary care physicians: do guidelines make a difference? Am J Kidney Dis. 2006;47(1):72-7.

12. Tseng CL, Kern EF, Miller DR, et al. Survival benefit of nephrologic care in patients with diabetes mellitus and chronic kidney disease. Arch Intern Med. 2008;168(1):55-62. 
13. Philipneri MD, Rocca Rey LA, Schnitzler MA, et al. Delivery patterns of recommended chronic kidney disease care in clinical practice: administrative claims-based analysis and systematic literature review. Clin Exp Nephrol. 2008;12(1):41-52.

14. Stevens PE, O'Donoghue DJ, de Lusignan S, et al. Chronic kidney disease management in the United Kingdom: NEOERICA project results. Kidney Int. 2007;72(1):92-9.

15. Minutolo R, Sasso FC, Chiodini P, et al. Management of cardiovascular risk factors in advanced type 2 diabetic nephropathy: a comparative analysis in nephrology, diabetology and primary care settings. J Hypertens. 2006;24(8):1655-61.

16. Levey AS, Bosch JP, Lewis JB, Greene T, Rogers N, Roth D. A more accurate method to estimate glomerular filtration rate from serum creatinine: a new prediction equation. Modification of diet in renal disease study group. Ann Intern Med. 1999;130(6):461-70.

17. National Committee For Guality Assurance Web Site. HEDIS and quality measurement. http://www.ncqa.org/tabid/59/Default.aspx. Accessed September, 14, 2010.

18. KDOQI. Clinical practice guidelines and clinical practice recommendations for diabetes and chronic kidney disease. Am J Kidney Dis. 2007;49 (2 Suppl 2):S12-154.

19. Dinneen SF, Gerstein HC. The association of microalbuminuria and mortality in non-insulin-dependent diabetes mellitus. A systematic overview of the literature. Arch Intern Med. 1997;157(13):1413-8.

20. Gerstein HC, Mann JF, Yi $\mathbf{Q}$, et al. Albuminuria and risk of cardiovascular events, death, and heart failure in diabetic and nondiabetic individuals. Jama. 2001;286(4):421-6.

21. Fox CH, Swanson A, Kahn LS, Glaser K, Murray BM. Improving chronic kidney disease care in primary care practices: an upstate New York practice-based research Network (UNYNET) Study. J Am Board Fam Med. 2008;21(6):522-30.

22. Akbari A, Swedko PJ, Clark HD, et al. Detection of chronic kidney disease with laboratory reporting of estimated glomerular filtration rate and an educational program. Arch Intern Med. 2004;164(16):1788-92.

23. Rutkowski M, Mann W, Derose S, et al. Implementing KDOQI CKD definition and staging guidelines in Southern California Kaiser Permanente. Am J Kidney Dis. 2009;53(3 Suppl 3):S86-99.

24. Go AS, Chertow GM, Fan D, McCulloch CE, Hsu CY. Chronic kidney disease and the risks of death, cardiovascular events, and hospitalization. N Engl J Med. 2004;351(13):1296-305.

25. Smith DH, Gullion CM, Nichols G, Keith DS, Brown JB. Cost of medical care for chronic kidney disease and comorbidity among enrollees in a large HMO population. J Am Soc Nephrol. 2004; 15(5):1300-6.

26. Parikh NI, Hwang SJ, Larson MG, Meigs JB, Levy D, Fox CS. Cardiovascular disease risk factors in chronic kidney disease: overall burden and rates of treatment and control. Arch Intern Med. 2006;166 (17): 1884-91.

27. Snyder JJ, Collins AJ. KDOQI hypertension, dyslipidemia, and diabetes care guidelines and current care patterns in the United States CKD population: National Health and Nutrition Examination Survey 19992004. Am J Nephrol. 2009;30(1):44-54.

28. Minutolo R, De Nicola L, Zamboli P, et al. Management of hypertension in patients with CKD: differences between primary and tertiary care settings. Am J Kidney Dis. 2005;46(1):18-25.
29. Hoy T, Fisher M, Barber B, Borker R, Stolshek B, Goodman W. Adherence to K/DOQI practice guidelines for bone metabolism and disease. Am J Manag Care. 2007;13(11):620-5.

30. Rocco MV. Disease management programs for CKD patients: the potential and pitfalls. Am J Kidney Dis. 2009;53(3 Suppl 3):S56-63.

31. Sequist TD, Fitzmaurice GM, Marshall R, et al. Cultural competency training and performance reports to improve diabetes care for black patients: a cluster randomized, controlled trial. Ann Intern Med. 2010;152(1):40-6.

32. Wyatt C, Konduri V, Eng J, Rohatgi R. Reporting of estimated GFR in the primary care clinic. Am J Kidney Dis. 2007;49(5):634-41.

33. Hemmelgarn BR, Manns BJ, Lloyd A, et al. Relation between kidney function, proteinuria, and adverse outcomes. Jama. 303(5);423-429.

34. Winkelmayer WC, Glynn RJ, Levin R, Owen WF Jr, Avorn J. Determinants of delayed nephrologist referral in patients with chronic kidney disease. Am J Kidney Dis. 2001;38(6):1178-84.

35. Mendelssohn DC, Kua BT, Singer PA. Referral for dialysis in Ontario. Arch Intern Med. 1995;155(22):2473-8.

36. O'Hare AM, Hailpern SM, Pavkov ME, et al. Prognostic implications of the urinary albumin to creatinine ratio in veterans of different ages with diabetes. Arch Intern Med. 170(11):930-936.

37. Foy R, Hempel S, Rubenstein L, et al. Meta-analysis: effect of interactive communication between collaborating primary care physicians and specialists. Ann Intern Med. 2010;152(4):247-58.

38. Chertow GM, Lee J, Kuperman GJ, et al. Guided medication dosing for inpatients with renal insufficiency. JAMA. 2001;286(22):283944.

39. Jain A, Atreja A, Harris CM, Lehmann M, Burns J, Young J. Responding to the rofecoxib withdrawal crisis: a new model for notifying patients at risk and their health care providers. Ann Intern Med. 2005; 142(3): 182-6.

40. Rodondi N, Peng T, Karter AJ, et al. Therapy modifications in response to poorly controlled hypertension, dyslipidemia, and diabetes mellitus. Ann Intern Med. 2006;144(7):475-84.

41. Patel TV, Singh AK. Kidney disease outcomes quality initiative guidelines for bone and mineral metabolism: emerging questions. Semin Nephrol. 2009;29(2):105-12.

42. Unger EF, Thompson AM, Blank MJ, Temple R. Erythropoiesisstimulating agents-time for a reevaluation. N Engl J Med. 2010;362 (3): 189-92.

43. K/DOGI. Clinical practice guidelines on hypertension and antihypertensive agents in chronic kidney disease. Am J Kidney Dis. 2004;43(5 Suppl 1):S1-290.

44. Chobanian AV, Bakris GL, Black HR, et al. The seventh report of the joint national committee on prevention, detection, evaluation, and treatment of high blood pressure: the JNC 7 report. Jama. 2003;289 (19):2560-72.

45. Appel L, Wright JT, Greene T, et al. Intensive blood-pressure control in hypertensive chronic kidney disease. N Eng J Med. 2010;363(10):91827.

46. Jafar TH, Stark PC, Schmid CH, et al. Progression of chronic kidney disease: the role of blood pressure control, proteinuria, and angiotensinconverting enzyme inhibition: a patient-level meta-analysis. Ann Intern Med. 2003;139(4):244-52. 